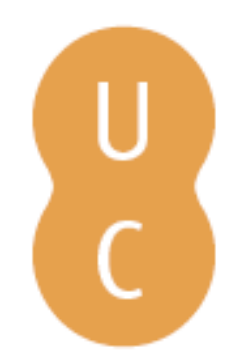

\title{
nombalina
}

\section{Contributos da detecção remota para a evidência e localização de pegmatitos em contexto intragranítico: Ponte da Barca (Minho)}

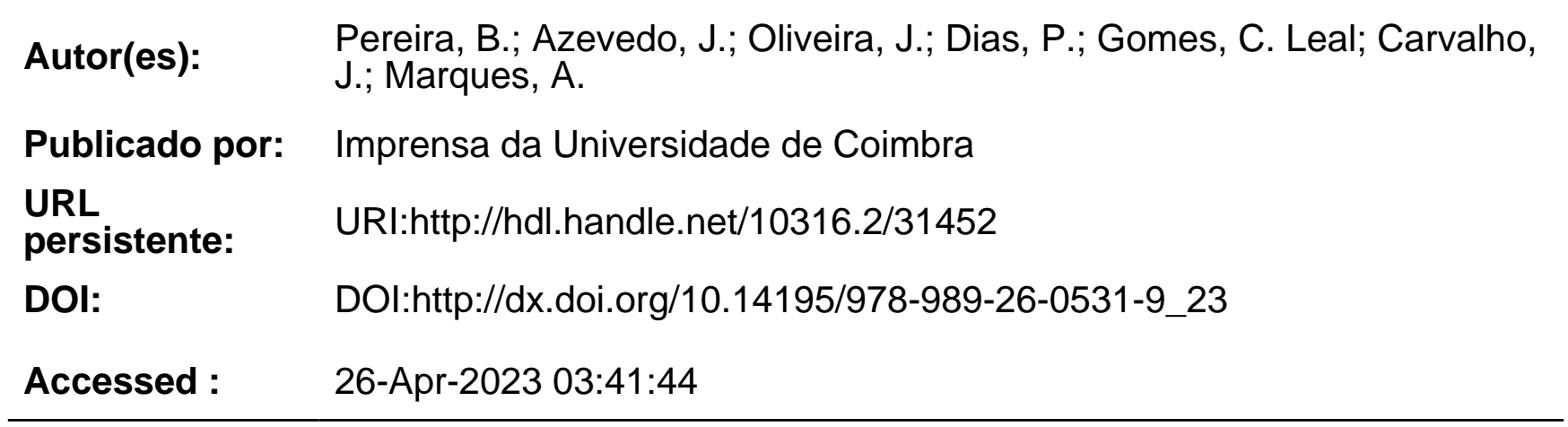

A navegação consulta e descarregamento dos títulos inseridos nas Bibliotecas Digitais UC Digitalis, UC Pombalina e UC Impactum, pressupõem a aceitação plena e sem reservas dos Termos e Condições de Uso destas Bibliotecas Digitais, disponíveis em https://digitalis.uc.pt/pt-pt/termos.

Conforme exposto nos referidos Termos e Condições de Uso, o descarregamento de títulos de acesso restrito requer uma licença válida de autorização devendo o utilizador aceder ao(s) documento(s) a partir de um endereço de IP da instituição detentora da supramencionada licença.

Ao utilizador é apenas permitido o descarregamento para uso pessoal, pelo que o emprego do(s) título(s) descarregado(s) para outro fim, designadamente comercial, carece de autorização do respetivo autor ou editor da obra.

Na medida em que todas as obras da UC Digitalis se encontram protegidas pelo Código do Direito de Autor e Direitos Conexos e demais legislação aplicável, toda a cópia, parcial ou total, deste documento, nos casos em que é legalmente admitida, deverá conter ou fazer-se acompanhar por este aviso.

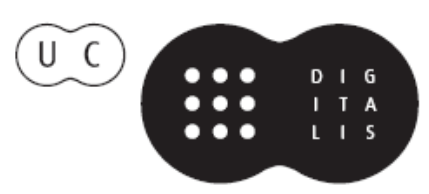





\title{
CONTRIBUTOS DA DETECÇÃO REMOTA PARA A EVIDÊNCIA E LOCALIZAÇÃO DE PEGMATITOS EM CONTEXTO INTRA-GRANÍTICO - PONTE DA BARCA (MINHO)
}

\author{
CONTRIBUTION OF REMOTE SENSING TO THE EVIDENCE \\ AND LOCATION OF GRANITE HOSTED PEGMATITES \\ - PONTE DA BARCA (MINHO)
}

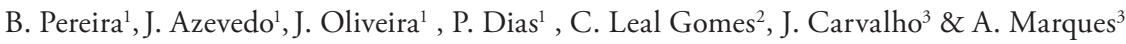

Resumo - Em contexto de prospecção de bolsadas pegmatíticas hospedadas em granitos da regiáo de Ponte da Barca, procurou-se, combinando técnicas de análise distanciada e levantamento de campo, detectar interfaces litológicas com as quais se pudesse relacionar a organização espacial e estrutural dos pegmatitos aí aflorantes. A evidência de alinhamentos curvilíneos em imagens do Landsat, sobretudo bem marcados nas imagens que resultam da aplicação de algoritmos de classificação Maxver, são compatíveis com a existência de fluidalidades planares ou plano-lineares concêntricas, possivelmente herdadas de plumas de "ballooning", verificando-se uma correlação espacial entre a localização dos pegmatitos e as suas periferias, que separam domínios diferenciados de "clustering" de fenocristais.

Palavras-chave - Pegmatitos; Detecção remota; Alinhamentos curvilíneos; Plumas de "ballooning"; Invariância escalar

Abstract - Within the context of prospecting operations of pegmatite bodies hosted in granites in the Ponte da Barca region, we sought to detect lithologic interfaces from which the relationship between the spatial and structural organization of the outcropping pegmatite bodies could be established, by combining field work and remotely sensed data analysis. The evidence of curvilinear alignments in LANDSAT imagery, especially well-marked in the images obtained from the application of classification algorithms, are compatible with the

\footnotetext{
${ }^{1}$ Sinergeo, Lda - Edifício IEMinho, Lugar de Casal, 4730-575, Soutelo, VILA VERDE; geral@sinergeo.pt

2 DCT, Universidade do Minho - Campus de Gualtar, 4710-057, BRAGA; caal.gomes@gmail.com

3 GGC, Lda - Rua Cunha Jr., 41 - B - s 1.6, 4250-186, PORTO, jhc@ggconsult.com.pt
} 
existence of concentric planar or plan-linear fluidalities, possibly inherited from ballooning plumes. We thus verified a spatial correlation between the pegmatite outcrops and ballooning plumes peripheries, which separate different domains of phenocristaline clustering.

Keywords - Pegmatites; Remote sensing; Curvilinear alignments; Ballooning; Scalar invariance

\section{1 - Introduçáo}

No âmbito das atividades de I\&DT da empresa Sinergeo Lda., encontra-se em curso o projecto PROSPEG dedicado à investigação em prospecção e pesquisa de pegmatitos graníticos, apoiado pela Agência de Inovaçáo ao abrigo do QREN, tendo como co-promotora a Universidade do Minho e consultora a empresa Geologia Geotecnia Consultores Lda.

É objetivo geral do projeto o desenvolvimento de articulaçốes em interface entre a prospecção geológica e a análise distanciada, com vista à detecçáo remota de pegmatitos com potencial interesse económico, procurando a quantificação da expressão morfológica, cromática, textural e espectral de corpos pegmatíticos e seus indícios aflorantes e guias de prospecçấo (PEREIRA et al., 2011).

Em estádio estratégico as açôes de prospecção incidem sobre um conjunto de áreas-chave que são, reconhecida ou hipoteticamente, férteis no que respeita à ocorrência de pegmatitos com interesse económico comprovado. Essas áreas podem ser encaradas como compartimentos da Província Pegmatítica Varisca do Norte e Centro de Portugal, onde ocorrem classes e tipos de pegmatitos em situaçóes intra a exo-graníticas, com uma grande diversidade estrutural, morfométrica, mineralógica e económica.

$\mathrm{Na}$ região do Minho, concentraram-se os trabalhos de prospecção numa área que faz parte dos concelhos de Ponte da Barca e Terras de Bouro, onde se reconhecem numerosas exploraçôes de quartzo abandonadas. Algumas destas exploraçôes foram convertidas mais recentemente para a produção de agregados, a partir dos granitos hospedeiros.

Trabalhos anteriores dedicados ao estudo dos pegmatitos aí aflorantes, descrevem a sua morfologia, estrutura interna e paragénese e sugerem alguns guias úteis para prospecção (SILVA, 2002).

Na expectativa de contribuir para a dedução de um método de evidência de minerais cerâmicos pegmatíticos e admitindo uma relação estreita entre a instalação das bolsadas e a sua localização, morfometria e morfoscopia, combinou-se um estudo de análise distanciada, com recurso a imagens multiespectrais do sensor LANDSAT e imagens disponibilizadas pelo Google Earth Pro, combinada com levantamentos cartográficos de pormenor em alvos remotos revelados. A manipulação das imagens de satélite operou-se através do "software" SPRING (CAMARA et al., 1996).

\section{2 - Estudo da distribuição regional das ocorrências pegmatíticas}

Os pegmatitos que ocorrem na regiāo de Ponte da Barca são, essencialmente, bolsadas intra-graníticas, mais ou menos isodiamétricas ou irregulares, de dimensões variáveis 
(SILVA, 2002). Trata-se de corpos zonados com quartzo muito abundante ( $\mathrm{z}>\mathrm{Fk})$ que na classificação de GINSBURG et al., (1979) correspondem a pegmatitos cerâmicos, dominantemente potássicos sem grandes unidades tardias e com unidades estruturais internas hiperaluminosas (SILVA, 2002).

A cartografia geológica relativa à área em estudo encontra-se na folha 5-B - Ponte da Barca - à escala 1:50000 de TEIXEIRA et al. (1974).

Aí encontram-se representadas as principais manchas correspondentes à discriminação regional entre litótipos graníticos. Distinguem-se os granitos de duas micas, predominantemente biotíticos, inferidos como calco-alcalinos, que incluem conjuntos de fácies dominantemente porfiroides, relativamente aos granitos, referidos como alcalinos, náo porfiroides.

A distribuição das manchas de fácies contrastantes, tal como se observam na carta 5B, apresenta-se, por decalque e conversão vectorial, na Fig. 1.

A Sul, o granito porfiroide de grão grosseiro ou médio a grosseiro $(\mathrm{g} \pi \mathrm{g})$ é predominante. Do ponto de vista petrográfico apresenta fenocristais de feldspato alcalino com cor branca, dimensão grosseira. Os conteúdos de biotite são variáveis. Relacionam-se com estas fácies, alguns encraves microgranulares de composição intermédia, dioríticos a tonalíticos. $\mathrm{Na}$ sua área de afloramento notam-se ainda faixas de grande concentração de corpos básicos filonianos equivalentes a lamprófiros e microdioritos. A dispersão de atitudes dos filóes organiza-se em famílias de azimutes ENE-SSW, NE-SW e NW-SE.

Na mesma Fig. 1, a Norte, afloram granitos não porfiroides com variabilidade petrográfica significativa. Além de importantes modificaçôes na granulometria que levam a separar fácies de grão médio a grosseiro $\left(\mathrm{g}^{\prime} g\right)$ das fácies com grão médio a fino $\left(\mathrm{g}^{\prime} \mathrm{m}\right)$, ainda se observam variaçôes nos conteúdos modais de biotite.

Também se reconhecem ocasionais faixas de encraves de rochas metassedimentares representadas perto do limite entre granitos "calcoalcalinos" e "alcalinos" junto dos pegmatitos de Pedra da Moura. Como referem LEAL GOMES \& LOPES NUNES (2003) e LEAL GOMES et al., (2009, 2010), a proliferação destes corpos pode indiciar que a produtividade pegmatítica neste local se deve a processos de contaminaçáo em consequência de "mixing" e "mingling", o que também é apoiado pela existência de micro-concentraçôes de horneblenda observadas no estudo petrográfico de fácies graníticas situadas na proximidade dos corpos pegmatíticos (SILVA, 2002). 


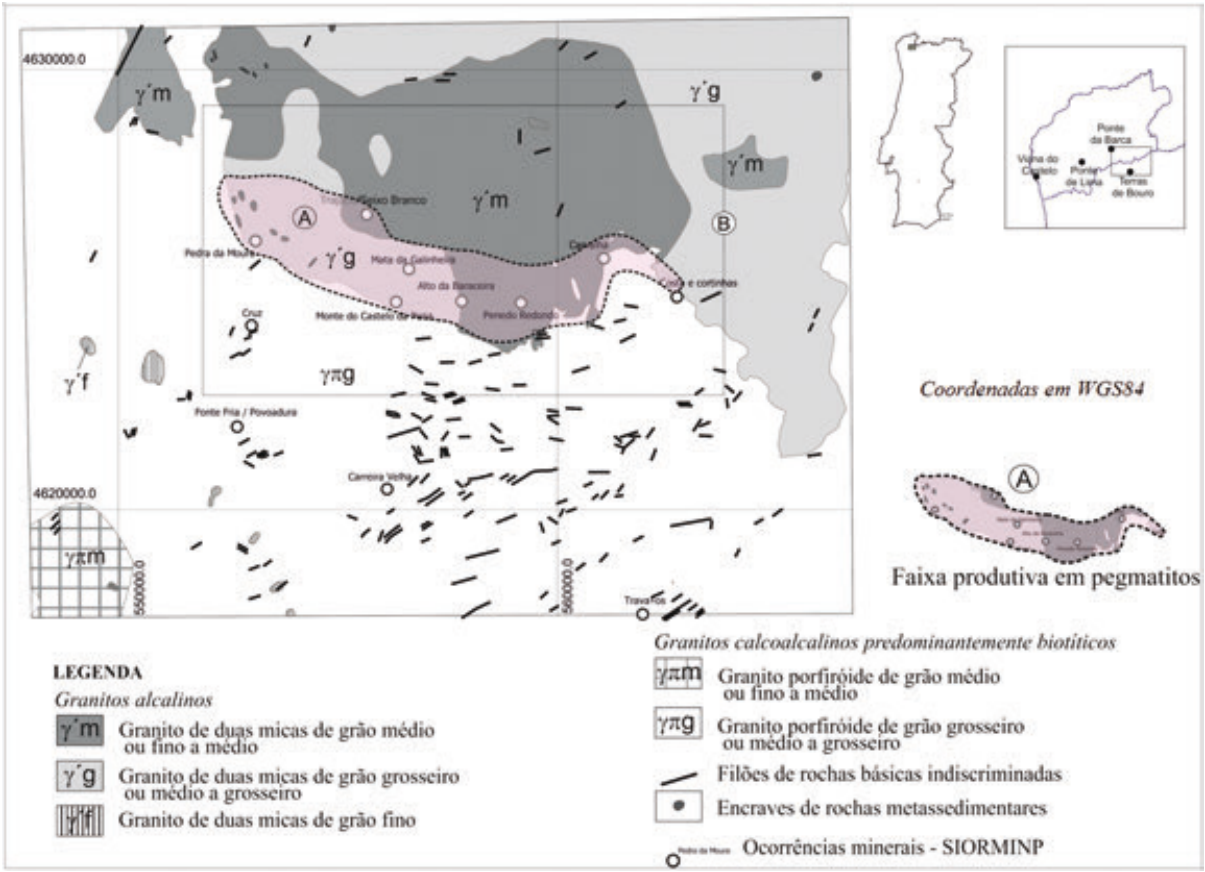

Fig. 1 -Distribuição das concessões mineiras antigas dedicadas ao quartzo e feldspato no sector do campo pegmatítico de Ponte da Barca em relação com a cartografia das fácies graníticas patente na folha $5 \mathrm{~B}$. Delimitaçấo de uma faixa produtiva em pegmatitos ao longo de um contacto múltiplo litológico na área abrangida por este estudo e assinalada com a letra A.

A distribuição de índices pegmatíticos e a sua relação com as manchas graníticas, pode refletir a existência de faixas produtivas graníticas cogenéticas. Conjugando os dados de distribuição das concessóes mineiras dedicadas ao quartzo e feldspato, patentes na base de dados SIORMINP (2011), com a cartografia geológica da folha $5 \mathrm{~B}$, percebe-se que a concentração cartográfica de índices pegmatíticos é mais consistente ao longo de um contacto múltiplo descrito como uma faixa, que acompanha os granitos $\mathrm{g}^{\prime} g$ e $\mathrm{g}^{\prime} m$ na interface com a mancha maior de afloramento da fácies $\mathrm{g} \pi g$ (Fig.1).

A faixa produtiva, delimitada na Fig. 1, deduzida a partir daquela conjunção, pode ser equivalente a um corredor de implantação de granitos cogenéticos, na sua porção apical. Tendências de evolução magmática primária, às quais se associa potencialmente, uma fraccionação pegmatítica, podem fornecer uma explicação para aquela organização espacial e estrutural.

\section{3 - Detecção remota após classificação de imagens em interfaces produtivas}

O estudo remoto das faixas de interface mais férteis por observação de imagens Landsat - bandas individuais e combinaçóes RGB - realçadas por aumento de contraste 
linear, permitiu pôr em evidência alguns alinhamentos, cujo traçado poderá depender de factores relacionados com entidades estruturais ou mineralógicas.

São perceptíveis em fotointerpretação, utilizando variaçôes das intensidades de cinzentos e do contraste, alinhamentos com definição megaescalar que seguem direçóes NNE-SSW e NW-SE, correspondentes possivelmente a estruturas de cisalhamento frágil atribuíveis à tectónica tardi-Varisca.

Outros alinhamentos perceptíveis em análise distanciada, correspondem a limites ou linhas de variação cromática e textural dos objetos à superfície; têm desenho fundamentalmente curvilíneo, por vezes concêntrico e concentram-se ao longo da principal faixa produtiva (Fig. 2A; cenário 1). Observa-se uma vizinhança entre estas configuraçóes e a distribuição de alguns pegmatitos explorados.

Aplicando algoritmos de classificação de imagem Maxver (máxima verosimilhança) às bandas 2, 3 e 4 do Landsat e utilizando como guias para atribuiçáo de pixéis algumas indicações chave provenientes da análise estrutural, obteve-se a imagem com cores artificiais da Fig. 2B (cenário 2). Estão aí representadas 3 cores contrastantes, que definem manchas as quais do ponto de vista espectral correspondem melhor aos granitos porfiroides (1), aos granitos de grão médio a fino (2) e a fácies porfiroides muito finas e lineamentares (3).

A extração de lineamentos a partir da imagem obtida por classificação realça os alinhamentos curvilíneos notados nas observaçóes anteriores (fig. 2B; cenário 2), permitindo deduzir ainda outras situaçôes com a mesma expressão geométrica que não eram aparentes sem a imagem tratada. Estes alinhamentos curvilíneos parecem pois resultar de contraste composicional e litológico, separando, grosseiramente, domínios diferenciados de "clustering" de fenocristais. Parece existir alguma correlação espacial entre a localização dos pegmatitos e os invólucros mais periféricos dos conjuntos de alinhamentos.

A restituição do cenário 1 à morfologia em Google-Earth (Fig. 2 C; cenário 3) é compatível com a existência de fluidalidades planares ou plano-lineares concêntricas intersectadas pela superfície topográfica em níveis elevados, eventualmente herdadas das protuberâncias de cúpula (plumas de "ballooning") cortadas pela erosão, parecendo que as bolsadas pegmatíticas se localizam na sua periferia. 


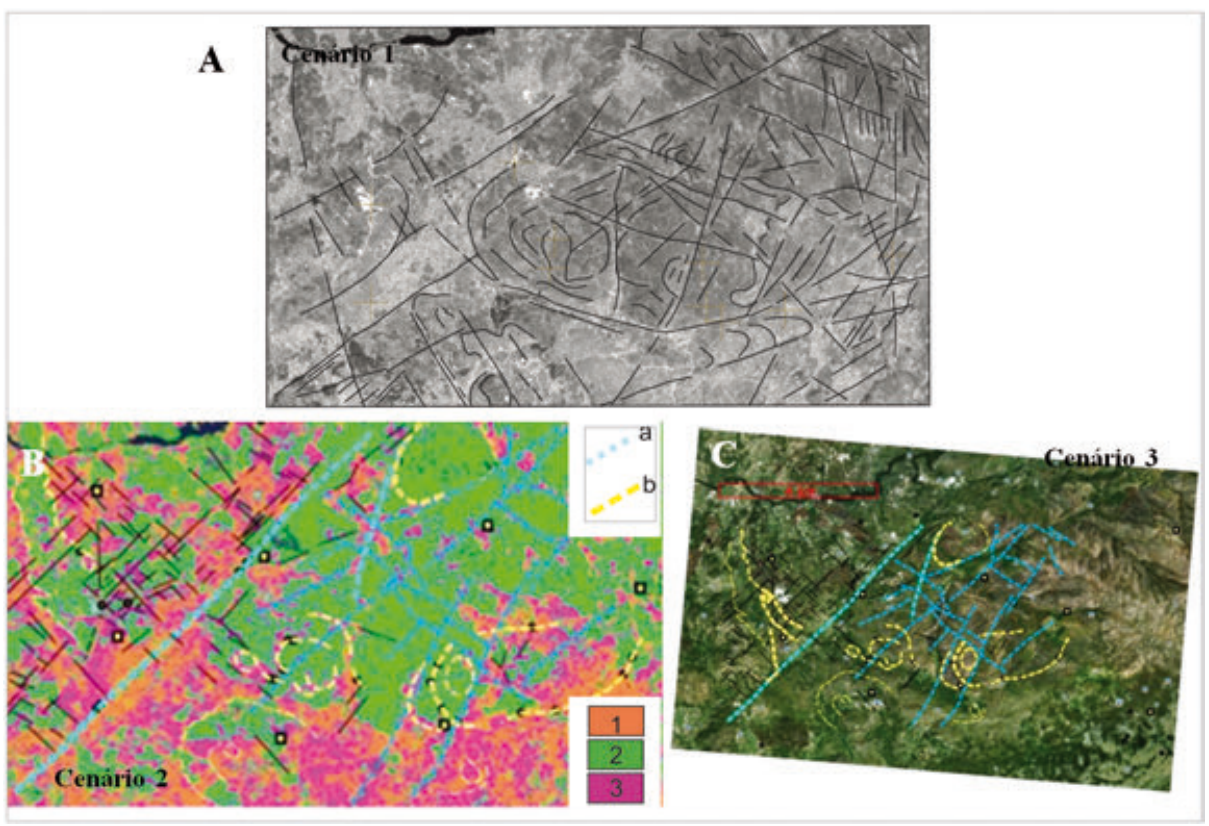

Fig. 2 - A - Extracção de limites lineares e curvilíneos por fotointerpretação a partir de imagens remotas do satélite Landsat, lançados sobre uma imagem em tons de cinzento correspondente à sua banda pancromática (cenário 1); B - Imagem obtida por classificação Maxver de pixéis representativos de afloramentos de granitos porfiróides (1), granitos de grão médio a fino indiscriminados (2) e granitos lineamentares (3), com a localização das principais bolsadas pegmatíticas exploradas e extracção dos alinhamentos evidentes (a- limites lineares correspondentes a estruturas de cisalhamento frágil e dúctil-frágil, b-alinhamentos curvilíneos relacionados com "ballooning”) (cenário 2). C - Restituição do cenário 2 à imagem do Google-Earth (cenário 3). Os limites da área correspondem ao campo B da Fig.1.

\section{4 - Cartografia detalhada}

Elegeram-se áreas mais restritas para cartografia de pormenor com base na proliferação de alinhamentos curvilíneos estabelecidos nas imagens remotas.

Nestes sectores cartografados às escalas 1:5000 e 1:10000, além dos litótipos graníticos regionais descritos na cartografia 1:50000 publicada, identificaram-se novos tipos petrográficos, tendencialmente anómalos, que gradualmente transitam para as fácies regionais, e cuja disposição aproximadamente aureolar se parece relacionar com algumas geometrias estabelecidas à distância.

No sector de Germil (Fig. 3A) a transição entre o granito porfiroide g $\pi g$ e a fácies de grão fino a médio, predominantemente leucocrata $\left(\mathrm{g}^{\prime} \mathrm{m}\right)$, expressa-se pelo enriquecimento progressivo em biotite na fácies porfiroide da faixa de contacto. Sobre-concentraçôes de biotite aqui localizadas podem alcançar valores modais próximos de 70\% (Fig.4 A). Uma explicação para a sua origem deve ser encontrada nas dinâmicas de fluxo e deslocação de fundentes. 
Por hipótese, equilíbrios geoquímicos entre estes níveis refractários ainda impóem uma especialização hiperaluminosa aos corpos pegmatíticos aflorantes no interior da mancha granítica de grão fino, onde é tipomórfica a andaluzite e eventualmente o corindo, em massas volumetricamente consideráveis formuladas perto do núcleo de quartzo das bolsadas.

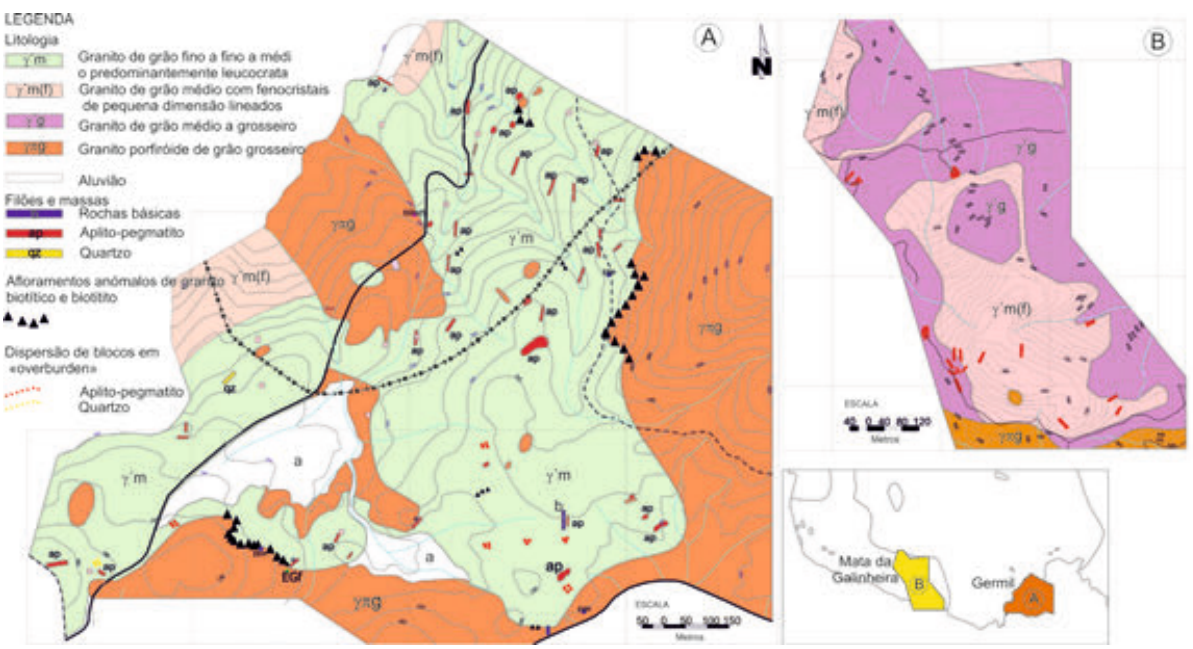

Fig. 3 - Cartas de pormenor obtidas em levantamentos de campo nos sectores de Germil (A) e Mata da Galinheira (B).

Na área da Mata da Galinheira (Fig. 3B) observa-se a transição gradual entre o granito de grão médio a grosseiro $g^{\prime} g$ e uma fácies porfiroide com fenocristais de feldspato potássico de pequena dimensão que surgem normalmente a definir uma lineação penetrativa (Fig. 4B). Nesta fácies lineamentar, com posicionamento mais ou menos cupular relativamente aos granitos envolventes, o arranjo geométrico dos fenocristais de feldspato potássico poderá ser funcional para o estabelecimento de componentes de fluxo magmático - fluidalidades lineares e planares. Nota-se também que a distribuição dos pegmatitos revela um carácter coincidente com os limites envolventes de proliferação de fluidalidades convolutas.

$\mathrm{Na}$ Fig. 4 apresentam-se alguns aspectos estruturais observados em afloramento, que parecem ter carácter chave para a interpretação das superfícies limite curvilíneas aparentes nas imagens do Landsat. 
A

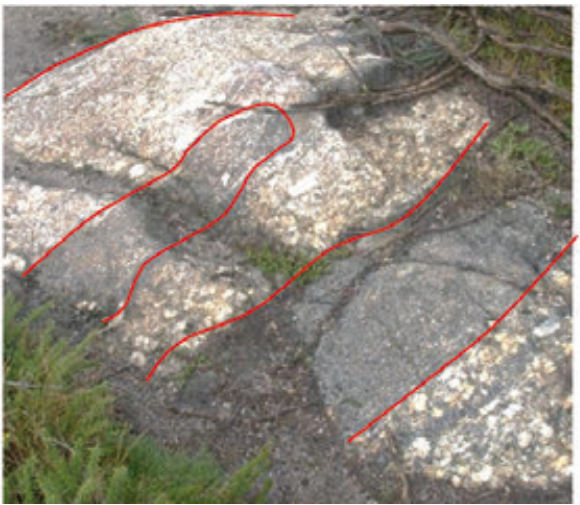

B

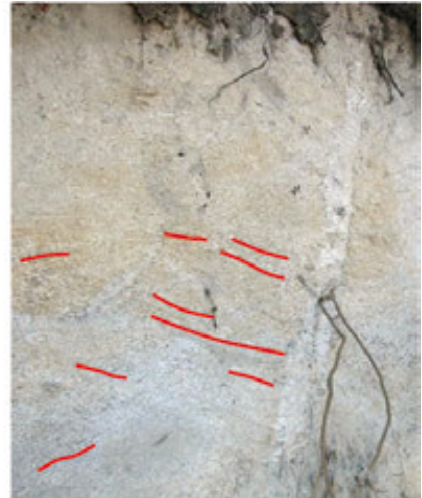

Fig. 4 - Aspectos estruturais observados em afloramentos dos sectores de Germil (A) e Mata da Galinheira (B) - "clustering" de fenocristais. Ver explicação no texto.

\section{5 - Reconstituição geométrica}

Como hipótese a proliferação de imagens de fluidalidades convolutas pode corresponder à expressão em afloramento de plumas de ascensão magmática diferenciada por "ballooning", em resposta a eventuais contrastes de viscosidade e densidade dos diferenciados graníticos cogenéticos.

Com o intuito de obter um cenário 3D para a organização de plumas de "ballooning" e sua estruturação face às superfícies erosivas atuais, operou-se, uma manipulação em Google Earth Pro com distorção do cenário 2 (Fig. 2C) para um contexto 3D que é apresentado na Fig. 5.

A reconstituição tridimensional das estruturações primárias em pluma e "ballooning" está patente nas Fig. $5 \mathrm{~B}$ e C.

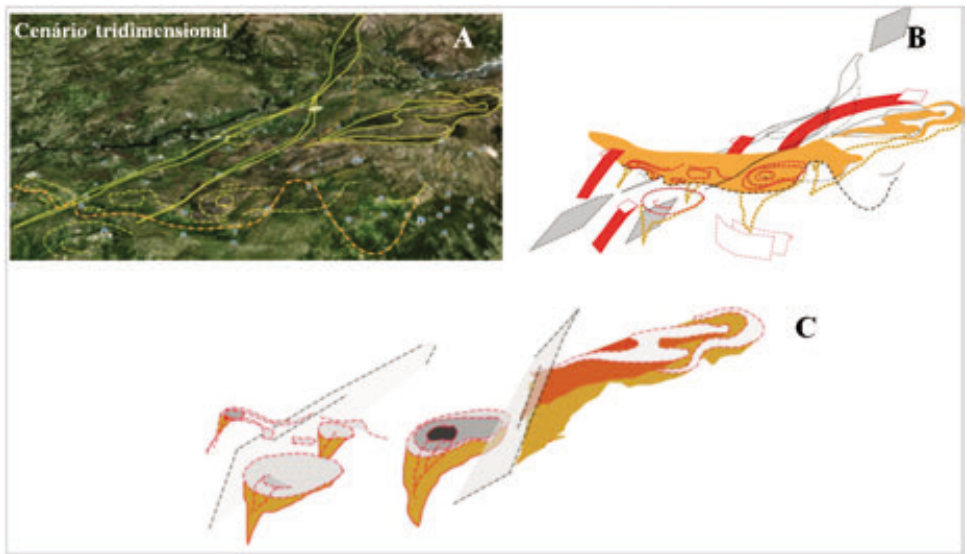

Fig. 5 - Reconstituição geométrica 3D da organização de plumas de "ballooning" intra-granítico na zona de contacto produtivo, deduzidas a partir de alinhamentos curvilíneos perceptíveis em análise distanciada. 
A simulação das relaçóes de intrusão também sugere o condicionamento tectónico responsável pela deslocação das trajetórias de fluxo, segundo um alinhamento gerado em regime dúctil, NE-SW. Esta hipótese sugerida anteriormente por SILVA (2002) para explicar o extravasamento lateral para SE das bolsadas pegmatíticas em gota invertida, após modelação tridimensional das morfologias de alguns pegmatitos deste sector, parece agora, também controlar a implantação e conformação de plumas de "ballooning" intra-granítico na zona de contacto.

Verifica-se ainda que as organizaçóes de alinhamentos curvilíneos observados à escala da manipulação das imagens de satélite, não são espúrias podendo eventualmente ser reconhecidas em contexto mesoescalar.

Se vier a verificar-se válida a invariância escalar, GUIMARÁES \& LEAL GOMES (2010) documentam um dispositivo em afloramento, em Castelo de Aboim perto da Mata da Galinheira, em que as geometrias limite, curvilíneas, que separam domínios diferenciados de "clustering" de fenocristais, poderiam ser do mesmo tipo genético das que se observam em análise distanciada (Fig. 6).

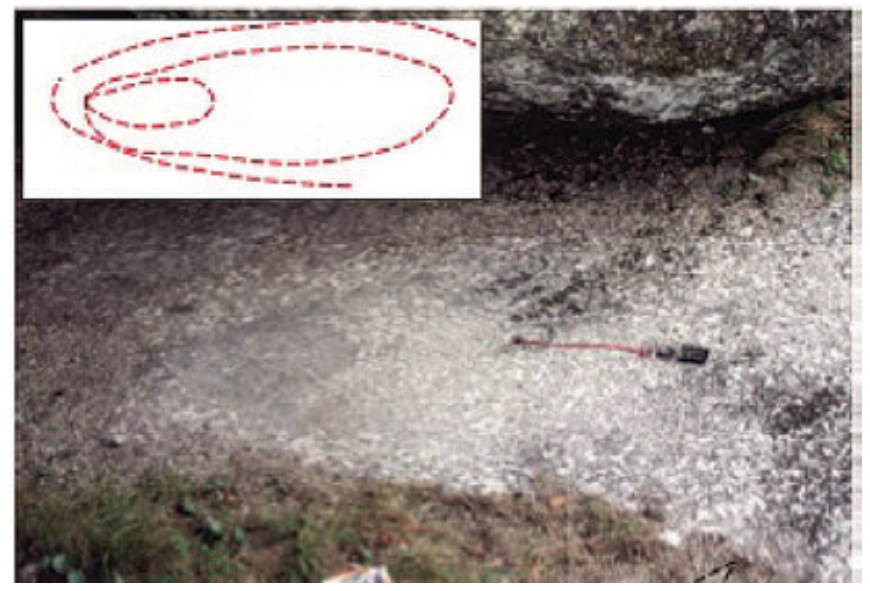

Fig. 6 - Dispositivo mesoescalar com evidência de domínios diferenciados de "clustering" de fenocristais, observado em Castelo de Aboim (GUIMARĀES \& LEAL GOMES, 2010)

Assim, a existência de trajetórias de fluxo, mais ou menos convolutas, e a possibilidade da sua detecção em análise distanciada pode ser uma via para a detecção remota de bolsadas pegmatíticas. Esta hipótese, é, petrogeneticamente, coerente, pois pressupóe a possibilidade de fraccionação mais eficaz, onde sob condicionamento tectónico, é mais intensa a deslocação dos fundentes e diferenciados deles resultantes, por fraccionação, nas câmaras magmáticas.

\section{Referências Bibliográficas}

CAMARA, G; SOUZA, R.C.M.; FREITAS, U. M. \& GARRIDO, J (1996) - Integrating remote sensing and GIS by object-oriented data modeling. Computers \& Graphics, 20, 3, p. 395-403. 
GINSBURG, A. I.; TIMOFEYEV, I. N. \&FELDMAN, L. G. (1979) - Principles of Geology of the granitic pegmatites. Nedra, Moscovo.

GUIMARÃES, D. \& LEAL GOMES, C. (2010) - Evolução de forma e implantação de pegmatitos intra-graníticos Variscos - N de Portugal. I - dispositivos ascensionais. e-Terra, Geosciences on-line Journal, Geotic, vol 11.

LEAL GOMES, C. (2010) - Distribuição espacial dos recursos de materiais cerâmicos pegmatíticos no Noroeste de Portugal - Matriz orogénica e metalogénese relacionada. Ciências Geológicas - Ensino, Investigação e sua História, vol II, p.25-36.

LEAL GOMES, C., AZEVEDO, A., LOPES NUNES, J. \&, DIAS, P.A. (2009) - Phosphate fractionation in pegmatites of Pedra da Moura II claim - Ponte da Barca - Portugal. Estudos Geológicos (Special Issue of contributions to the 4th International Symposium on Granitic Pegmatites), vol. 19 (2):172-176.

LEAL GOMES, C. \& LOPES NUNES, J. E. (2003) - Análise paragenética e classificação dos pegmatitos graníticos da Cintura Hercínica Centro-Ibérica. A geologia de Engenharia e os Recursos Geológicos, Coimbra - Imprensa da Universidade, vol. II, p. 85-109.

PEREIRA, B; AZEVEDO, J.; OLIVEIRA, J.; DIAS, P.; LEAL GOMES, C.; CARVALHO, J.\& MARQUES (2011) - PROSPEG - Prospecção, Análise Distanciada e Detecçấo Remota de Pegmatitos. In: Martins, L.M.P., Oliveira, D.P.S., Silva, R., Viegas, H.M.C., Villas Bôas, R. C. (eds). Valorizaçâo de pegmatitos litiníferos. Lisboa, Portugal, p. 78-79.

SILVA, V. (2002) - Qualificação dos recursos de minerais cerâmicos pegmatíticos. Tese de Mestrado, Universidade do Minho, 151p.

SIORMINP (2011) - Base de dados de ocorrências minerais em Portugal. LNEG. http:/geoportal.lneg.pt/arcgis/ services/OcorrenciasMinerais/MapServer/WMSServer?request=GetCapabilities\&service=WMS. (consultado em 2011.05.10).

TEIXEIRA, C.; MEDEIROS, A. \& TEIXEIRA LOPES, J. (1974) - Folha 5-B da carta geológica de Portugal na escala 1:50000. Serviços Geológicos de Portugal, Lisboa, 61 p. 